\title{
A PRODUÇÃO DE CONHECIMENTO EM POLÍTICAS EDUCACIONAIS DOS PROGRAMAS DE PÓS-GRADUAÇÃO EM EDUCAÇÃO DA UNIVERSIDADE ESTADUAL PAULISTA
}

\author{
Kellcia Rezende SOUZA ${ }^{1}$ \\ Maria Teresa Micely KERBAUY ${ }^{2}$
}

Resumo: O presente estudo analisa as tendências subjacentes as pesquisas em políticas educacionais na produção dos programas de Pós-Graduação em Educação da Universidade Estadual Paulista (Unesp). Para tanto, foi realizada uma pesquisa bibliográfica com enfoque qualitativo. Os dados foram analisados a partir dos conteúdos dos resumos. Tomamos como objeto para compreender esta problemática as dissertações e teses, com temáticas voltadas para a área da política educacional. Foram selecionadas 85 pesquisas, no período de 2009 à 2013. Os trabalhos traduzem o panorama de tendências e olhares predominantes no campo das políticas educacionais dos programas da instituição, representado no quadro de 5 categorias temáticas: Estudos sobre políticas e programas governamentais; Legislação e direito à educação; Políticas de financiamento e gestão; Políticas de avaliação e Papel dos partidos políticos e outras entidades da sociedade civil. A análise empreendida demonstra os avanços do campo de conhecimento focalizado e os limites que se apresentam para a consolidação da área.

Palavras-chave: Pesquisas. Política educacional. Pós-graduação.

\section{INTRODUÇÃO}

Um espaço significativo para a produção de conhecimento do campo educacional consiste na Universidade e, consequentemente, na Pós-graduação, exatamente pela centralidade que nos programas ocupa a prática da pesquisa. Por isso, há a necessidade de avaliação do que vem sendo desenvolvido, em termo de produção de conhecimento nos programas de Pós-graduação, uma vez que estes, historicamente, se concretizam em locus privilegiados pelo sistema educacional brasileiro para o desenvolvimento da pesquisa científica.

Os cursos de mestrado e doutorado constituem um espaço privilegiado de produção do conhecimento e que os estudos sobre a política educacional têm ocupado lugar emergente no seio da Pós-graduação em Educação, objetivamos investigar as

\footnotetext{
${ }^{1}$ Doutoranda em Educação Escolar. UNESP - Universidade Estadual Paulista. Faculdade de Ciências e Letras. Araraquara - SP - Brasil. 14800-901 - kellcia@ hotmail.com.

${ }^{2}$ Docente de Pós-Graduação em Educação Escolar. UNESP - Universidade Estadual Paulista. Faculdade de Ciências e Letras. Araraquara - SP - Brasil. 14800-901 - kerbauy@ travelnet.com.br.
} 
tendências subjacentes as pesquisas em políticas educacionais na produção dos programas de Pós-Graduação em Educação da Universidade Estadual Paulista (Unesp).

Para tanto, foi realizada uma pesquisa bibliográfica com enfoque qualitativo. A análise dos dados, mediante a classificação, foi realizada com base na análise dos conteúdos dos resumos, buscando identificar os elementos em comum dos trabalhos. Tomamos como objeto para compreender esta problemática as dissertações e teses, com temáticas voltadas para a área da política educacional.

O estudo se sustenta no objetivo de conhecer os diferentes enfoques e caminhos já trilhados pelas pesquisas que refletem a política educacional. A busca se justifica por sua capacidade de oferecer um panorama abrangente da produção acadêmica sobre o tema no campo educacional da Pós-Graduação da Unesp e, assim, contribuir para o avanço do conhecimento.

No que concerne aos programas de Pós-Graduação em Educação (stricto sensu), podemos perceber a significativa expansão a partir dos dados da avaliação da Coordenação de Aperfeiçoamento de Pessoal de Nível Superior (CAPES) disponíveis em seu portal (BRASIL, 2014), No triênio 2001 a 2003 foram avaliados 68 programas, número que praticamente dobrou no período de 2007 à 2009, totalizando 122 programas.

Conforme dados disponibilizados no portal da respectiva instituição, em 2014, há 154 programas e 225 cursos de Pós-graduação em Educação (stricto sensu), englobando os oferecidos na modalidade profissional. A região Sudeste dispõe da maior quantidade de programas, totalizando 50, destes, 24 estão localizados no Estado de São Paulo $^{3}$. A Unesp oferece 4 programas na área da Educação, nos campus de Araraquara, Marília, Presidente Prudente e Rio Claro.

A escolha da Unesp se deu, pois as pesquisadoras estão vinculadas a instituição. Dessa forma, compreender a realidade que está inserido constitui premissa singular para uma compreensão macro do fenômeno. Ademais, trata-se de uma universidade pública com expressivo destaque nas atividades de ensino, extensão e, sobretudo, pesquisa. É a única instituição, das três universidades públicas paulistas, que está presente em todas as regiões do estado (FONSECA-JANES, 2010).

\section{Panorama das pesquisas em políticas educacionais dos programas de Pós- Graduação na área de educação da Unesp}

${ }^{3}$ Não foram computados os programas de pós-graduação na modalidade profissional. 
A Unesp, com seus quatro programas de Pós-Graduação na área de Educação, todos com atividades iniciadas a mais de $10 \operatorname{anos}^{4}$ e com linhas de pesquisas sobre a temática tem contribuído decisivamente para o incremento de formação de pesquisadores e, consequentemente, da produção de conhecimentos no campo educacional, permitindo assim, compreender os múltiplos fenômenos da educação.

Nessa perspectiva, o estudo foi desenvolvido mediante análise das pesquisas resultantes dos programas de Mestrado e Doutorado em Educação da Unesp - Campus de Araraquara, Marília, Presidente Prudente e Rio Claro, no qual, a partir do olhar de vários autores, encontramos subsídios para oferecer uma visão representativa do que se produziu sobre a área de políticas educacionais.

A composição do campo amostral se deu em um primeiro momento por um inventário das produções, em seguida, foi realizada a seleção daquelas que atenderam aos seguintes critérios: (a) tratar da política educacional enquanto problemática da educação brasileira; (b) reportar-se ao período de 2009-2013 ou à fração dele; (c) ser de natureza acadêmica-científica; (d) estar disponibilizada em banco de dados eletrônicos ${ }^{5}$. Os trabalhos classificados foram selecionados por pesquisas oriundas de programas de pós-graduação em Educação da Unesp - Campus de Araraquara, Marília, Presidente Prudente e Rio Claro, que englobam teses de doutorado e dissertações de mestrado.

Buscou-se investigar as pesquisas que evidenciavam nos títulos, resumos e palavras-chave a presença das expressões: Política educacional; Política Pública; Estado; Governo e Legislação; Projetos e programas governamentais; Partidos políticos e Entidades sindicais. A partir desse levantamento, foi selecionado um universo de 37 teses e 48 dissertações, totalizando 85 trabalhos. Importa-nos salientar o fato de que esse dado expressa que a categoria de "Políticas Educacionais" tem respondido um número significativo de pesquisas no período investigado.

As produções foram analisadas a partir da leitura dos seus respectivos resumos. Reconhecemos as limitações impostas na análise dos resumos, pois nem sempre estes deixam transparecer a amplitude das discussões travadas no corpo do trabalho. No entanto, considerando que, ainda com essas restrições, os resumos devem evidenciar as intencionalidades, os contornos das abordagens teóricas, os caminhos metodológicos e os resultados das pesquisas, dando indicativos para o olhar do objeto investigado.

\footnotetext{
${ }^{4}$ Os programas de Pós-graduação na área de educação da Unesp de Marília, Araraquara, Presidente Prudente e Rio Claro iniciaram suas atividades respectivamente em 1988, 1997, 2001, 2003.

${ }^{5}$ Portal eletrônico dos programas e Capes.
} 
O movimento do conhecimento produzido sobre a política educacional nas dissertações e teses dos programas de Pós-Graduação em Educação da Unesp, inicialmente, nos leva a registrar a dificuldade evidenciada no percurso de análise dos dados, em virtude da heterogeneidade dos conteúdos do resumo, que apresentavam falta de informações concernentes ao caminho metodológico e genéricas considerações sobre os resultados das investigações, realidade que também foi constatada no estudo de Wittmann e Gracindo (2001). Esse fato foi evidenciado em maior proporção nas dissertações, do que nas teses. Como o mestrado corresponde a etapa inicial de formação de pesquisadores, tende a apresentar níveis de menor complexidade no desenvolvimento das pesquisas, o que pode comprometer o grau qualitativo da produção.

No que tange ao período temporal da produção, nota-se que o ano de 2010 contemplou a maior quantidade, totalizando 25 trabalhos, o que significa quase o dobro, se comparado ao ano anterior. Porém, o número não se estabiliza nos anos seguintes, destacando uma acentuada queda na quantidade trabalhos.

Além disso, há uma assimetria entre a quantidade de pesquisas vinculadas aos programas. Por serem mais antigos e, consequentemente, mais consolidados, os Programas de Araraquara e Marília ${ }^{6}$ concentram o maior número de produções no período, respectivamente 26 e 37 pesquisas. Em contrapartida, os Programas de Presidente Prudente e Rio Claro ${ }^{7}$ somam 22 trabalhos, ambos com 11 cada. Estes últimos, respectivamente, passaram a oferecer cursos de Doutorado a partir do ano de 2010 e 2012.

Verificamos também, que a maior incidência de trabalhos focaliza a educação básica, ao todo 60 pesquisas. No que tange as etapas da educação básica, o Ensino Fundamental é a que abarca a maioria das produções, totalizando 35, enquanto que a Educação Infantil compreende 9 e o Ensino Médio 4. Os demais trabalhos investigaram mais de uma etapa da educação básica.

Como podemos notar, mais da metade dos trabalhos estão voltados para o Ensino Fundamental. Tal predominância reflete, em certa medida, a focalização desta etapa, como a que mais tem expressado preocupação dos pesquisadores. Identifica-se

\footnotetext{
${ }^{6}$ No período delimitado para o estudo, o Programa de Pós-Graduação em Educação da Unesp de Marília realizou o doutorado interinstitucional em educação (DINTER), a partir de um convênio com a Universidade Federal do Maranhão (UFMA). As produções resultantes desse projeto também foram analisadas.

${ }^{7}$ Não está disponível na página do programa e no portal da Capes as produções de 2013.
} 
também o pequeno número de pesquisas sobre a Educação Infantil e a baixíssima produção referente ao Ensino Médio expressam um dado preocupante, que pode refletir não só a pequena prioridade das políticas educacionais voltadas para essas etapas, como também o escasso interesse por investigá-las.

O pequeno número de produção de conhecimento sobre a Educação Infantil e Ensino Médio demonstra a assimetria existente entre as opções de objeto de estudo, o que pode indicar uma limitação no campo das políticas educacionais, comprometendo uma perspectiva analítica da totalidade e as múltiplas relações que estão envolvidas nesse campo científico.

A disparidade de proporção de pesquisas também é constatada, quando comparamos com a quantidade de trabalhos que tratam da política educacional para o Ensino Superior e demais modalidades educacionais. Com a incidência menor, identificamos 15 produções concernentes ao Ensino Superior e 8 sobre as modalidades (Educação de Jovens e adultos - EJA; Educação à distância - EaD; Educação Especial e Educação Tecnológica e Profissional).

Embora nos últimos anos foi possível evidenciar a expansão da educação superior e tecnológica pública e privada, mediante políticas e programas (Reestruturação e Expansão das Universidades Federais - Reuni; Programa Universidade para Todos - Prouni; Programa Nacional de Acesso ao Ensino Técnico e Emprego - Pronatec, dentre outros), trata-se de um dado que expressa que os fenômenos têm sido pouco investigados, assim, limitando o desenvolvimento de parâmetros analíticos que tragam mais densidade as produções (SILVA; OURIQUE, 2012).

Souza (2003) aponta que as lacunas evidenciadas no processo de construção da área de política pública merecem atenção especial, para que a partir dessas limitações sejam envidados esforços para superá-las, pois essa dinâmica se constitui em fator decisivo para o desenvolvimento científico alavancado da área.

Em face desse quadro, salientamos que os estudos sobre as políticas educacionais voltadas para o Ensino Superior e as modalidades de ensino vêm merecendo abordagem crescente, em vista de sua relevância história, social e política no cenário educacional brasileiro. Logo, o desenvolvimento de projetos e provimento de financiamentos se constituem condições basilares, para que esses fenômenos correspondam percentuais expressivos de investigação. 
Quanto a abrangência das questões investigadas, notamos que a predominância de investigações sobre a realidade da política educacional nos municípios paulistas, em especial, aqueles onde estão situados os programas. Por outro lado, há um percentual significativo de estudos concernentes a fenômenos de outros estados brasileiros e até de outros países, o que demonstra a contribuição para ampliação de investigações nos mais diferentes contextos. Além do impacto acadêmico e social, essas características levam os Programas a ter uma projeção em nível nacional e internacional.

\section{Tendências temáticas das pesquisas em políticas educacionais dos programas de Pós-Graduação na área de educação da Unesp}

Procedida a análise dos 85 resumos, deparamos nos trabalhos com uma ampla abordagem de distintas temáticas, o que, para Azevedo e Aguiar (2001) pode representar dois caminhos opostos: o primeiro condiz com a possibilidade de um debate amplo sobre os mais diversos temas da política educacional; o segundo, induz a reflexão referente a carência de aprofundamento dos temas da área.

Frente a essa realidade, optamos por classificar os trabalhos nas seguintes categorias: Estudos sobre políticas e programas governamentais; Legislação e direito à educação; Políticas de avaliação; Papel dos partidos políticos e outras entidades da sociedade civil e Políticas de financiamento e gestão (Tabela 1). É importante destacar que, a classificação das dissertações e teses em categorias para esta pesquisa corresponde a uma estratégia analítica que visa delimitar com mais precisão as interfaces que são comuns aos campos de investigação, porém, não invalida a presença de outras dimensões de análise, com maior ou menor nível de profundidade.

Tabela 1 - Quantidade de trabalhos analisados por temáticas

\begin{tabular}{lc}
\hline \multicolumn{1}{c}{ Temática Geral } & Quantidade \\
\hline $\begin{array}{l}\text { Estudos sobre programas e projetos } \\
\text { governamentais }\end{array}$ & 24 \\
Legislação e direito à educação & 21 \\
Políticas de avaliação & 12 \\
$\begin{array}{l}\text { Papel dos partidos políticos e outras entidades } \\
\text { da sociedade civil }\end{array}$ & 6 \\
Políticas de financiamento e gestão & 22 \\
\hline TOTAL & 85 \\
\hline
\end{tabular}

Fonte: Elaboração própria. 
Observamos que os trabalhos cujo foco principal corresponde as análises sobre programas e projetos governamentais, correspondem a maioria. Nessa categoria, encontram estudos sobre programas e projetos educacionais implantados nas esferas: municipal, estadual e federal, bem como, diretrizes de organismos internacionais, tais como: Fundo Monetário Internacional (FMI), Banco Mundial (Bird), Organização das Nações Unidas para a Educação, Ciência e Cultura (UNESCO).

Segundo esses dados, podemos notar que nessa categoria encontram as principais tendências do estado da arte das pesquisas sobre política educacional nos programas da área na Unesp. A maior parte dos estudos é caracterizada como pesquisas documentais e de campo. Entretanto, percebe um número significativo de estudos de casos, principalmente, no que tange a esfera municipal, que se pautam em questionar como são implementadas os programas e projetos nas redes de ensino e escolas.

Destaca-se também a vasta distribuição de abordagem de temas, as pesquisas analisam programas e projetos relativos a formação de professores, gestão, alfabetização, planejamento e currículo. Observamos com maior incidência, dentre os que foram objetos dos estudos, os seguintes programas: Programa Nacional Biblioteca da Escola (PNBE); Programa Nacional de Inclusão de Jovens (Projovem); Programa Nacional do Livro Didático $(P N L D)$; Programa Nacional de Integração da Educação Profissional com a Educação Básica na Modalidade de Educação de Jovens e Adultos (Proeja); Programa de Ensino Integral - SP e Programa São Paulo Faz Escola.

Observamos que os trabalhos desse grupo têm mais claramente um núcleo comum de interesses, configurando um maior grau de organicidade entre eles, expressando assim, a prioridade que os programas e projetos assumem nas agendas dos governos federal, estadual e municipal, como estratégias para contemplar as políticas educacionais.

Na categoria "políticas de financiamento e gestão", situam-se pesquisas sobre o processo de implantação de políticas de democratização e processos de descentralização no âmbito dos sistemas de ensino e nas escolas, assim como, discussões concernentes a políticas de investimentos, ou seja, a regulamentação da arrecadação e distribuição dos recursos públicos destinados à educação.

Situam-se pesquisas que têm o objetivo de investigar políticas de reformas de gestão nos sistemas de ensino e nas escolas, a partir de definições macro e micro das políticas educacionais. Registramos que as produções fazem referências as condições de implementação do processo de municipalização, no que tange a estratégias para a 
descentralização, auto-gestão e autonomia. Assim como constatado no estudo de Oliveira e Teixeira (2001), a tese da municipalização desenvolveu-se aliada a concepção de descentralização.

Merece também destaque as discussões atinentes ao fenômeno da gestão democrática e os mecanismos de participação colegiada (Análise das repercussões de eleições de diretores de escolas, da participação popular e dos conselhos) e a focalização das investigações voltadas à educação básica, mais especificamente, ao Ensino Fundamental e Educação Infantil.

Ademais, nesse grupo, constam os trabalhos que tem como objeto o financiamento, com a parcela maior de estudos sobre as questões postas pelas políticas nacionais, dentre elas, destacam-se: o Fundo de Manutenção e Desenvolvimento do Ensino Fundamental e de Valorização do Magistério (FUNDEF) e Fundo de Manutenção e Desenvolvimento da Educação Básica e de Valorização dos Profissionais da Educação (FUNDEB), que são analisados pela ótica de equidade e eficiência na alocação distributiva dos recursos e aplicação das verbas. Porém, chama a atenção o significativo percentual de produções concernentes ao debate da privatização do ensino, bem como, das parcerias resultantes dos convênios público-privadas.

Por outro lado, as pesquisas sobre financiamento educacional deixaram de contemplar o Ensino Superior. A fim de alcançar aprofundamento sobre a temática, parece que falta ampliar o leque de temas tratados e uma aproximação critica com maior vigor no que tange a equidade e eficiência de ensino.

A educação como direito se inscreve no campo das políticas públicas e a existência de um direito implica sempre a existência de um sistema normativo, tal pressuposto foi crucial para definirmos a categoria "legislação e direito à educação", no qual figuram a terceira maior quantidade de produções. Aqui incluem trabalhos sistematizados após a LDB n. 9394/1996, leis orgânicas, direitos constitucionais, direitos humanos, políticas de combate à exclusão - as ações afirmativas, educação inclusiva e para Educação de Jovens e Adultos (EJA).

Nesse grupo, observa-se que vários trabalhos que buscaram interpretar o conteúdo do texto legal, procurando expor a compreensão dos processos que engendram as decisões das políticas educacionais, em articulação com outras políticas estatais e municipais, bem como, com o contexto social mais amplo no qual elas vão incidir. Em número menor, encontram-se os estudos decorrentes de análises sobre o direito à 
educação, levando-se em conta a relevância que a educação adquire na construção do demais direitos.

Particularmente, nos últimos anos, se considerarmos as contínuas alterações que vem sofrendo a ordem legal de garantia da ampliação da escolaridade obrigatória, reflexos do Ensino Fundamental de nove anos e da expansão constitucional do direito à educação a população de 4 à 7 anos, esta temática pode representar a vitalidade e atualidade da temática na agenda das produções sobre a política educacional brasileira.

Quanto aos estudos sobre política de avaliação, destacam a abordagem de temas sobre a avaliação de programas, projetos, políticas e organizações educativas, bem como, a análise dos sistemas de avaliação de largas escalas. Nessa categoria, observamos a equidade das pesquisas no que concerne aos níveis de ensino. Há uma predominância de investigações sobre o Sistema de Avaliação da Educação Básica (Saeb) e Sistema Nacional de Avaliação da Educação Superior (Sinaes) e suas interfaces com a universidade e escola.

Há que se ressaltar a abordagem, ainda que em menor número, da política de avaliação externa, expressada por investigações que analisam o Índice de Desenvolvimento da Educação Básica (Ideb) e o seu impacto para definição de diretrizes das políticas educacionais que objetivem a melhoria da qualidade do ensino.

Denota-se que o menor percentual de produções concerne as da categoria papel dos partidos políticos e outras entidades da sociedade civil. Neste grupo, enfatizam pesquisas sobre a relação dos partidos com a implantação de políticas educacionais e a influência dos movimentos sociais da sociedade civil.

Os estudos priorizaram a investigação da gestão dos partidos políticos e municípios e no estado de São Paulo, dentre eles, destaca-se o Partido dos Trabalhadores (PT) e o Partido da Social Democracia Brasileira (PSDB). No que concerne aos movimentos sociais, observamos a incidência da abordagem sobre os movimentos sindicais e o Movimento dos Trabalhadores Sem Terra (MST). Estas discussões indicam a presença de uma abordagem relevante para a compreensão da influência de grupos sociais organizados na definição de políticas a serem implantadas no cenário educacional.

No conjunto dos trabalhos, podemos observar uma simetria na abordagem dos temas de algumas categorias, embora seja bastante evidente a disparidade entre a categoria de papel dos partidos políticos e entidades da sociedade civil com as demais. Chama atenção este fato, pois são poucos os estudos que se preocupam com a 
investigação da interlocução das instituições genuinamente políticas, como os partidos e os movimentos organizados da sociedade civil, com a educação.

\section{Considerações finais}

Malgrado os limites desse tipo de estudo, em virtude de os dados resultarem dos resumos, a análise realizada permite afirmar a existência de um significativo acervo produzido na área de política educacional nos cinco anos aqui considerados. Pudemos evidenciar uma acentuada focalização de pesquisas voltadas para a educação básica, ao mesmo tempo em que tal aspecto pode indicar um aprofundamento acadêmico de conhecimento sobre a referida etapa, é também revelador da carência de discussões concernentes ao ensino superior e modalidades de ensino, o que pode incidir na limitação de quadros analíticos desses segmentos.

Constatamos um conjunto pulverizado de temáticas, que foram agrupadas nas categorias: Estudos sobre políticas e programas governamentais; Legislação e direito à educação; Políticas de financiamento e gestão; Políticas de avaliação e Papel dos partidos políticos e outras entidades da sociedade civil. Embora averiguamos uma certa equidade, com relação ao número de produções das três primeiras categorias, pode-se afirmar o pequeno grau de problematizações de temáticas nas categorias de Políticas de avaliação e, principalmente, do papel dos partidos políticos e outras entidades da sociedade civil.

As limitações evidenciadas no estudo não invalidam a significativa contribuição que os programas da Unesp oferecem para a construção e consolidação do campo de investigações das políticas educacionais. A diversidade de temas registrados é um indicador de avanços da área, sinalizando o progressivo amadurecimento acadêmicocientífico e consolidação desse campo no Brasil.

Esperamos, portanto, que este trabalho possa estimular o desenvolvimento de estudos sobre o mapeamento de fontes ainda não divulgadas no meio acadêmico, assim como a sistematização de análises sobre a constituição da área de políticas educacionais, a natureza de sua produção e a sua contribuição para o aprofundamento teórico e metodológico das análises.

\section{THE PRODUCTION OF KNOWLEDGE IN EDUCATIONAL POLICIES OF PROGRAMS POST GRADUATE IN EDUCATION THE UNIVERSITY STATE PAULISTA}


Abstract: This study examines the underlying trends research on educational policies in the production of graduate programs in Education at the Universidade Estadual Paulista (UNESP). To this end, a bibliographical research with qualitative approach was carried out. Data were analyzed from the abstracts content. We take as an object to understand this issue the dissertations and theses with theme focused on the area of educational policy. 85 studies were selected, from 2009 to 2013. The works reflect the view of prevailing trends and looks in the field of educational policies of the institution's programs, represented under 5 themes: Studies on government policies and programs; Legislation and the right to education; Financing policies and management; Assessment policies and role of political parties and other civil society organizations. The analysis undertaken shows the progress of the focused field of knowledge and the boundaries that appear to consolidate the area.

Key words: Research. Educational policy. Postgraduate studies.

\section{REFERÊNCIAS}

AZEVEDO, J. M. L.; AGUIAR, M. A. S. Políticas de educação: concepções e programas. In: WITTMANN, L. C.; GRACINDO, R. V. (Coord.). O estado da arte em política e gestão da educação no Brasil (1991-1997). Brasília: ANPAE; Campinas: Autores Associados, 2001. p.89-108.

BRASIL. CAPES - Coordenação de Aperfeiçoamento Pessoal de Nível Superior. Fundação CAPES. Brasília: Ministério da Educação, 2014. Disponível em: <http://www.capes.gov.br/>. Acesso em: 25 nov. 2014.

FONSECA-JANES, C. R. X. A formação dos estudantes de pedagogia para a educação inclusiva: estudo das atitudes sociais e do currículo. 2010. 269f. Tese (Doutorado em Educação) - Faculdade de Filosofia e Ciências, Universidade Estadual Paulista, Marília, 2010.

OLIVEIRA, C.; TEIXEIRA, L. H. G. Municipalização e gestão municipal. In: WITTMANN, L. C.; GRACINDO, R. V. (Coord.). O estado da arte em política e gestão da educação no Brasil (1991-1997). Brasília: ANPAE; Campinas: Autores Associados, 2001. p.133-150.

SILVA, J. P.; OURIQUE, M. L. H. A expansão da educação superior no Brasil: um estudo do caso Cesnors. Revista Brasileira de Estudos Pedagógicos, Brasília, v.93, n.233, p.215-230, jan./abr. 2012.

SOUZA, C. "Estado do campo" da pesquisa em políticas públicas no Brasil. Revista Brasileira de Ciências Sociais, São Paulo: ANPOCS: EDUSC, v.18, n.51, p.15-20, 2003.

WITTMANN, L. C.; GRACINDO, R. V. (Coord.). O estado da arte em política e gestão da educação no Brasil (1991-1997). Brasília: ANPAE; Campinas: Autores Associados, 2001. 